\title{
Effects of Short Term Inspiratory Muscle Training in Hospitalised Chronic Obstructive Pulmonary Disease Patients - An Experimental Study
}

\author{
Varun Naik $^{1^{*}}$, Vishagh Nair ${ }^{1}$ and S. Gautam ${ }^{2}$ \\ 'Department of Cardio Respiratory Physiotherapy, KAHER Institute of Physiotherapy, Belgaum, Karnataka, India; \\ varunnaik@klekipt.edu.in, vishaghnair@gmail.com \\ 2Department of Pulmonary Medicine, Jawaharlal Nehru Medical College, Belagavi - 590010, Karnataka, India; \\ docgautam6787@gmail.com
}

\begin{abstract}
Background: Chronic obstructive pulmonary (COPD) is a progressive irreversible lung disorder characterised by air way limitation which worsens on expiration and may additionally lead to compression of small airway ensuring air trapping in the lungs and subsequent hyperinflation. Objective: to evaluate the effects of short term muscle training in hospitalised chronic obstuctive pulmanory disease patients in terms of blood pressure heart rate PFT values functional cappacity. Methods: This study was a randomized control trial. A total number of participants participated in this study was $17(n=17)$ the purpose of the study was explained to the participants in their vernacular language and a written informed consent was obtained from all the subjects. Result: value $<0.05$ was considered as significant. This shows that majority of the subjects in the sample are of the age group "51-60 years" followed by "61-70 years" $12(70.59 \%)$ subjects in the sample are males, mean BMI of subjects in the sample is $26.29 \pm 5.23\left(\mathrm{~kg} / \mathrm{m}^{2}\right)$. $8(47.06 \%)$ of 17 subjects in the sample had normal BMI followed by $5(29.41 \%)$ had obesity and $4(23.53 \%)$ had overweight. mean respiratory rate of subjects in the sample is $24.06 \pm 3.58$.
\end{abstract}

Keywords: Chronic Obstructive Pulmonary Disease, Inspiratory Muscle Training

\section{Introduction}

Chronic obstructive pulmonary (COPD) is a progressive irreversible lung disorder characterised by air way limitation which worsens on expiration and may additionally lead to compression of small airway ensuring air trapping in the lungs and subsequent hyperinflation ${ }^{1}$. COPD is a common disorder pertaining to morbidity and mortality affecting the population aged 30 and above. More than 55.3 million people were diagnosed of COPD in $2016^{2}$. Globally COPD burden is projected to be greater in coming years because endured exposure to COPD hazards factors and ageing population ${ }^{2}$. The prevalence rate of COPD in India is $6.3 \%{ }^{3}$.

There are numerous effective treatment strategies for Airway clearance techniques for COPD which include the Postural Drainage (PD), Active Cycle of Breathing Technique (ACBT), Forced Expiration Technique (FET), Autogenic Drainage (ad), Positive Expiratory Pressure (PEP) Adjuncts Intermittent Positive Pressure Breathing (IPPB) ${ }^{3}$. ACBT includes tidal breathing, thoracic expansion exercises and forced expiration techniques which can be done in postural drainage positions or in sitting and can also be performed independently or with an assistant ${ }^{3}$.

Inspiratory muscle training is a form of resistance exercise which strengthens the muscles of respiration. When the respiratory muscles are strengthened regularly for a longer duration the patients will be able to exercise for a longer duration without being breathless.

Studies has shown that the utilization of IMT in pulmonary rehabilitation which improve lung function among patients with respiratory conditions. Maximal inspiratory pressure (PI max) is ordinarily used to check functional quality of the inspiratory muscles ${ }^{4}$. Early pulmonary rehabilitation programs which incorporate vigorous exercise, early ambulation, and IMT has been appeared to show positive results in COPD patients ${ }^{4}$. Diaphragm weakness is usually observed in patients of COPD and it is also a major reason to extend the sign of dyspnea and lower exercise capacity 5 . Prolonged inspiratory muscle weakness will reduce diaphragm strength which will lead to poor Quality Of Life (QOL) ${ }^{6}$.

${ }^{*}$ Author for correspondence 
Most of the previous studies conducted considered and showed a positive effect in 6 weeks to 12 months' duration. However, there are scares in effect of IMT in early rehabilitation. Also there is no literature available to test the effectiveness of IMT in 2 weeks. Hence the present study was formed to determine the effect of short term inspiratory muscle training in hospitalised patients with COPD. Objectives of the study was to determine and evaluate the effect of short term inspiratory muscle training in hospitalised patients with COPD in terms of Blood pressure \& Heart rate, PFT values and functional evaluation scale score.

\section{Methodology}

Ethical clearance was obtained from the Institutional Ethical Committee of from KAHER Institute of Physiotherapy, Belagavi. Subjects were diagnosed by the pulmonologist and were referred to the physiotherapist. Subjects were screened for inclusion and exclusion criteria and detailed demographic data of each subject was assessed. A written informed consent was obtained from the study participants. Intervention was given for 2 weeks 10 sessions. This study was a randomized control trial. A total number of participants participated in this study was $17(n=17)$ the purpose of the study was explained to the participants in their vernacular language and a written informed consent was obtained from all the subjects. Subjects were included in the study if they met the following inclusion criteria: 1) Diagnosed case OF COPD 2) Male and female aged between 30-50 years. 3) Smokers and non smokers4) clinically stable patients 5) and participants willing to participate in the study. Exclusion criteria were: 1) Resting SBP $>200 \mathrm{~mm} \mathrm{Hg}$ or DBP > 110 mm Hg. 2) Diagnosed cases of orthopnea. 3) Prehypertension and hypotension. 4) Diagnosed cases of chronic kidney diseases. 5) Injured musculoskeletal or fractured since 3 months. Subjects belonged to KLE tertiary care hospital Belgaum, Karnataka.

\section{Outcome Measures}

The study was done for 2 weeks, in which, pre and post test data of outcome measure were collected. Lungs function parameter such as FEV1, FEV1/FVC was measured using vitalograph COPD 6. Blood pressure and heart rate will be noted down during pre and post intervention. The Saint George's respiratory questioner was used to assess quality of life of patients it is designed to measure health impairment in patients with asthma and COPD. Four scores are calculated according to symptom, Activity, Impact, and Total. Lower score indicates better health. Blood pressure Outcome measures were assessed Pre - Post immediately after the first treatment session and at the end of 2 weeks.

\section{Intervention}

Inspiratory muscle training will be performed in semifowler's position. For the bronchial clearance in patients were performed slow expiration with an open glottis (eltgol), acceleration of expiratory flow and forced expiration; for the strengthening of the respiratory muscles the Threshold IMT. has been used. Each week pi max value of each subject will be assessed using spyrometer. BORG scale will be used for dyspnea measurement and will be evaluated pre and post for 2 weeks.

Intensity of training was $60-70 \%$ of Pi Max duration is 30 breaths, or 2 to 3 minutes' frequency is 5 times a week for 2 weeks.

\section{Result}

Data was analyzed using $\mathrm{R}$ software version 3.6 .2 and Excel. Categorical variables are given in the form of a table. Continuous variables were given in mean \pm sd form. Within group comparison was done using paired t-test/ Wilcoxon sign rank test. $\mathrm{P}$ value $<0.05$ was considered as significant (Table 1 ).

Table 1 shows that majority of the subjects in the sample are of the age group " $51-60$ years" followed by "61-70 years". $12(70.59 \%)$ subjects in the sample are males. mean BMI of subjects in the sample is $26.29 \pm 5.23\left(\mathrm{~kg} / \mathrm{m}^{2}\right) .8(47.06 \%)$ of 17 subjects in the sample had normal BMI followed by $5(29.41 \%)$ had obesity and $4(23.53 \%)$ had overweight. mean respiratory rate of subjects in the sample is $24.06 \pm 3.58$.

Table 1. Summary of the data

\begin{tabular}{|c|c|c|}
\hline Factor & Sub-category & Count (\%) \\
\hline \multicolumn{2}{|l|}{ Age (in years) } & $55.24 \pm 9.41$ \\
\hline \multirow{3}{*}{ Age group (in years) } & $41-50$ & $4(23.53 \%)$ \\
\hline & $51-60$ & $8(47.06 \%)$ \\
\hline & $61-70$ & $5(29.41 \%)$ \\
\hline \multirow{2}{*}{ Gender } & Male & $12(70.59 \%)$ \\
\hline & Female & $5(29.41 \%)$ \\
\hline \multicolumn{2}{|l|}{ Height (in cms) } & $157.88 \pm 8.25$ \\
\hline \multicolumn{2}{|l|}{ Weight (in kg) } & $66.18 \pm 14.5$ \\
\hline \multicolumn{2}{|l|}{ BMI $\left(\mathrm{kg} / \mathrm{m}^{2}\right)$} & $26.29 \pm 5.23$ \\
\hline \multirow{3}{*}{$\begin{array}{l}\text { BMI levels } \\
\text { (in } \mathrm{kg} / \mathrm{m}^{2} \text { ) }\end{array}$} & $18.5-24.9$ & $8(47.06 \%)$ \\
\hline & $25-29.9$ & $4(23.53 \%)$ \\
\hline & $\geq 30$ & $5(29.41 \%)$ \\
\hline \multicolumn{2}{|l|}{ Respiratory rate } & $24.06 \pm 3.58$ \\
\hline \multicolumn{2}{|l|}{ Years of diagnosis } & $6.35 \pm 1.84$ \\
\hline
\end{tabular}


Table 2. Effects of treatment pre and post on Pulmonary function, 6-minutewalk distance, Saint Gorge's Respiratory questioner, Maximum inspiratory pressure, Vital parameters

\begin{tabular}{|c|c|c|c|c|c|c|}
\hline \multirow{2}{*}{\multicolumn{2}{|c|}{ Factors }} & \multicolumn{2}{|c|}{ Time points } & \multirow{2}{*}{$\begin{array}{c}\text { Difference } \\
(\text { mean } \pm s d)\end{array}$} & \multirow{2}{*}{$\begin{array}{c}\text { Average } \% \text { of } \\
\text { increase }\end{array}$} & \multirow{2}{*}{ P-value } \\
\hline & & Pre & Post & & & \\
\hline \multicolumn{2}{|l|}{ FEV1 } & $1.12 \pm 0.43$ & $1.74 \pm 0.6$ & $0.62 \pm 0.44$ & $67.32 \%$ & $<0.0001^{\mathrm{PT}^{*}}$ \\
\hline \multicolumn{2}{|l|}{ FVC } & $2.04 \pm 1.1$ & $2.98 \pm 1.28$ & $0.94 \pm 0.75$ & $60.29 \%$ & $<0.0001^{\mathrm{PT}^{*}}$ \\
\hline \multicolumn{2}{|c|}{ FEV1:FVC ratio } & $0.63 \pm 0.31$ & $0.95 \pm 0.44$ & $0.32 \pm 0.45$ & $109.86 \%$ & $0.0044^{\mathrm{PT}^{*}}$ \\
\hline \multicolumn{2}{|c|}{ MIP } & $66.47 \pm 28.1$ & $87.94 \pm 34.33$ & $21.47 \pm 9.96$ & $38.02 \%$ & $<0.0001^{\mathrm{PT}^{*}}$ \\
\hline \multicolumn{2}{|c|}{ 6minute walk distance } & $126.06 \pm 17.33$ & $143.53 \pm 17.86$ & $17.47 \pm 7.06$ & $14.20 \%$ & $<0.0001^{\mathrm{PT}^{*}}$ \\
\hline \multirow{4}{*}{$\begin{array}{l}\text { SGRQ } \\
\text { Score }\end{array}$} & Symptom & $366.59 \pm 95.96$ & $319.18 \pm 90.52$ & $-47.41 \pm 103.46$ & $-12.93 \%$ & $0.0036^{\mathrm{WS}^{* *}}$ \\
\hline & Activity & $541.35 \pm 71.27$ & $479.06 \pm 58.68$ & $-62.29 \pm 51.28$ & $-10.99 \%$ & $0.0001^{\mathrm{WS}^{* *}}$ \\
\hline & Impact & $656.19 \pm 92.28$ & $637.94 \pm 91.67$ & $-18.25 \pm 23.35$ & $-2.77 \%$ & $0.0031^{\mathrm{WS}^{* *}}$ \\
\hline & Total & $1584 \pm 241.26$ & $1450 \pm 195.88$ & $-133.13 \pm 90.26$ & $-8.03 \%$ & $<0.0001^{\mathrm{PT}^{*}}$ \\
\hline \multicolumn{2}{|c|}{ Systolic blood pressure } & $115.88 \pm 12.78$ & $117.06 \pm 6.86$ & $1.18 \pm 9.93$ & $1.83 \%$ & $0.6171^{\mathrm{WS}^{* *}}$ \\
\hline \multicolumn{2}{|c|}{ Diastolic blood pressure } & $77.06 \pm 6.86$ & $79.41 \pm 7.48$ & $2.35 \pm 8.31$ & $3.52 \%$ & $0.2482^{\mathrm{WS}^{* *}}$ \\
\hline \multicolumn{2}{|c|}{ Heart rate } & $88.47 \pm 9.29$ & $93.24 \pm 10.94$ & $4.76 \pm 7.70$ & $5.63 \%$ & $0.0107^{\mathrm{PT}^{*}}$ \\
\hline \multicolumn{2}{|l|}{ SPO2 } & $93.94 \pm 5.01$ & $95.88 \pm 4.5$ & $11.94 \pm 3.85$ & $2.18 \%$ & $0.0033^{\mathrm{WS}^{* *}}$ \\
\hline
\end{tabular}

${ }^{*} \mathrm{PT}$ - paired T test

${ }^{* *}$ WS - Wilcoxon sign rank test

Lung function of the subjects were analysed using one tailed paired t-test, it has been concluded that mean of FEV1, FVC, ratio of FEV1: FVC, MIP is significantly more after the intervention compared to baseline. It has been observed that there is an average of $67.32 \%$ relative increase in FEV1 and there is an average of $60 \%$ relative increase in FVC during the intervention. Exercise tolerance of the subjects were analysed using paired $t$ test. It has been concluded that mean of increase in walking distance for 6 minutes significantly more than 0.05 . It has been observed that there is an average of $14.20 \%$ relative increase in walking distance for 6 minutes during the intervention.

Quality of life score were analysed Using Wilcoxon sign rank test, it has been concluded that SGRQ score (symptom, Activity, Impact) is significantly reduced from pre to post intervention. Using one tailed paired t-test, it has been concluded that mean of total SGRQ score significantly less after the treatment.

Hemodynamic function score was analysed Using Wilcoxon sign rank test, it has been concluded that there is no significant change in SBP and DBP during the intervention. However, there is an average of $1.83 \%$ and $3.52 \%$ relative increase in SBP and DBP levels which is not statistically significant. Using one tailed paired t-test, it has been concluded that mean of heart rate is significantly increased from pre to post during the intervention. There is an average of $5.63 \%$ and $2.18 \%$ relative increase in Heart rate and SPO2 during the intervention. Using Wilcoxon sign rank test, it has been concluded that $\mathrm{SPO} 2$ values are significantly increased from pre to post (Table 2 ).

\section{Discussion}

This study measured the effect of inspiratory muscle training in hospitalized COPD patient. The findings of this study revealed that there is an average of $67.32 \%$ relative increase in FEV1 and there is an average of $60 \%$ relative increase in FVC during intervention. The study also determines average of $14.20 \%$ relative increase in walking distance in 6 minutes' walk test.

This study also established improved quality of life, SPO2 values, heart rate but was insignificant in blood pressure level.

The present study is in consensus with the previous research conducted in INDIA about the gender prevalence with a domain of more affection in males (70.59\%) than females (29.41\%) in the study population. Male's previous study done in Kerala, southern India provided a gender prevalence of $6.73 \%$ and $5.67 \%$ among males and females respectively. However, our study had 12 male participants who made $70.59 \%$ of the study population and 5 females which made $29.41 \%$ of the study population.

A systemic review was done in 2002 which showed that the mean age of people having COPD was 65 ; another study done in the year 2000 showed that the mean age of subjects having COPD was 55 . However, our study showed that majority of the subjects were between the age group "51-60 years" followed by "61-70 years".

A study was conducted by Mariana Hoffman et al showed that inspiratory muscle training reduces dyspnea by improving diaphragm strength and improves inspiratory muscle function and quality of life in patient with COPD the results concluded 
that inspiratory muscle training was able to reduce dyspnea during activities of daily living as well as improving inspiratory muscle function and quality of life in patients with advance lung disease and these benefits were sustained for 3 months ${ }^{8}$. However, in our study Overall Quality of life is increased largely due to improvement of dyspnea in patients during $\mathrm{ADL}^{13}$.

A study was conducted for 2 weeks of inspiratory muscle training combine with chest physiotherapy in hospitalized COPD patients the results concluded that combination of inspiratory muscle training and chest physiotherapy provides superior effect on lung function, inspiratory muscle strength, exercise tolerance and quality of life among COPD patients?. However our study only used inspiratory muscle training for 2 weeks which showed improvement in 6 minute walk distance, lung function which contributed to the improvement in quality of life of patient.

Previous studies conducted in the year 2018 on the effects of Targeted Inspiratory Muscle Training Improves Respiratory Muscle Function and Reduces Dyspnea in Patients with Chronic Obstructive Pulmonary Disease, the results concluded that Targeted inspiratory muscle training enhanced respiratory muscle function and reduces dyspnea in symptomatic patients with moderate to severe chronic obstructive pulmonary disease $^{10}$.

A systematic review conducted on 2015 by E. Lynne Geddes et al on Inspiratory muscle training in adults with chronic obstructive pulmonary disease concluded that targeted inspiratory resistive, threshold or normocapneic hyperventilation IMT significantly increases inspiratory muscle strength and endurance, improves outcomes of exercise capacity, measure of quality of life and decreases dyspnea for adults with stable COPD ${ }^{11}$.

Kessler et al and Carr et al. observed that patients with COPD after exacerbation show a reduction in distance walked in the 6MWT. The earlier study showed that there is increased risk of hospitalization among these patients occurred in association with distance walked values is less than $367 \mathrm{~m}$, while in our study, it was observed that patients with episodes of exacerbation showed an average DW of $126.06 \pm 17.33 \mathrm{~m}$ pre-treatment and $143.53 \pm 17.86 \mathrm{~m}$ post treatment ${ }^{14}$.

Previous studies aimed at investigating the impact of obstructive ventilatory impairment on QoL in the elderly yielded divisive results some authors confirmed an improvement of QoL with age in COPD patients, presumably related to the fact that older subjects usually tend to restrict their own daily activity and expectations. In contrast, others suggest apersisting disease-related deterioration of quality of life in older COPD patients. In our study, SGRQ scores were significantly lower post treatment which suggests IMT improves $\mathrm{QOL}^{15}$.
It is possible that the specific exercise of the inspiratory muscles leads to changes in the structure of these muscles with an increase in the synthesis of contractile protein actin and myosin generating a greater capacity to produce strength.

\section{Limitations}

Most of the participants felt breathless while using inspiratory muscle trainer.

\section{Conclusion}

Current study concludes that IMT for 2-week duration produces beneficial effects for lung function with respect to, inspiratory muscle strength, exercise tolerance and quality of life among hospitalized mild to moderate COPD patient. Therefore, the study also would like to recommend threshold resistive IMT mode to be used as a part of physiotherapy treatments for treating patients with respiratory conditions especially for COPD.

\section{References}

1. Global Initiative for Chronic Obstructive Lung Disease (GOLD). Global Strategy for the diagnosis of chronic obstructive pulmonary disease. Medical Communication Resources, Barcelona, Spain.

2. Regional COPD working group. COPD prevalence in 12 AsisPacific countries and regions: Projections based on the COPD prevalence estimation model. Respirology. 2003; 8192-198.

3. Webber BA. The active cycle of breathing exercises. Cyst Fibrosis News. 1990.

4. Mikelsons C, Wedzicha W. Pulmonary rehabilitation and the COPD exacerbation. Semin Respir Crit Care Med. 2009; 30:64955. https://doi.org/10.1055/s-0029-1242634. PMid:19941222

5. Garrod R, Dallimore K, Cook J, et al. An evaluation of the acute impact of pursed lips breathing on walking distance in nonspontaneous pursed lips breathing chronic obstructive pulmonary disease patients. Chronic Respir Dis. 2005; 2(2): 67-72. https:// doi.org/10.1191/1479972305cd068oa. PMid:16279153

6. Clini E, Venturelli E, Crissafulli E. Rehabilitation in COPD patients admitted for exacerbation. Pneumonol Alegrgol Pol. 2011; 79:16-20.

7. McGavin CR, Gupta SP, Mc Hardy GJ. Twelve-minute walking test for assessing disability in chronic bronchitis. Br Med J. 1976; 1:822-3. https://doi.org/10.1136/bmj.1.6013.822. PMid:1260350. PMCid:PMC1639415

8. Mariana H. On the inspiratory muscle training reduces dyspnea during activity of daily living and improves inspiratory muscle function and quality of life in patient with COPD. CardiopulmRehabil Prev. 2009; 29:325-31. PMid:19561524. 
9. Ahmad $\mathrm{H}$, et al, Short term inspiratory muscle training combine with chest physiotherapy in hospitalized COPD patients. Crit Care Med. 2002; 166:111-17.

10. Andrew $\mathrm{H}$, et al. Targeted inspiratory muscle training improves respiratory muscle function and reduces dyspnea in patients with chronic obstructive pulmonary disease. Rev Port Penumol. 2008; 14:177-94. PMid:18363017

11. Geddes EL, et al. Inspiratory muscle training in adults with chronic obstructive pulmonary disease. Cardio Pulm Phys Ther J. 2009; 20:5-15. PMid:20467518. PMCid:PMC2845249.

12. Geddes EL, O’Brien K, Reid WD, Brooks D, Crowe J. Inspiratory muscle training in adults with chronic obstructive pulmonary disease: an update of a systematic review. Respir Med. 2009; 103:1240-1241. http://dx.doi.org/10.1016/j.rmed.2009.03.004.
13. O’Brien Kelly, Geddes EL, Reid WD, Brooks D, Crowe J. Inspiratory muscle training compared with other rehabilitation interventions in chronic obstructive pulmonary disease: A systematic review update. J Cardiopulm Rehabil Prev. 2008: 28:128-41. PMid:18360190. https://doi.org/10.1097/01. HCR.0000314208.40170.00. PMid:18360190

14. Homann D, Stefanello JMF, Góes SM, Leite N. Impaired functional capacity and exacerbation of pain and exertion during the 6-minute walk test in women with fibromyalgia. Rev Bras Fisioter. 2011; 15(6):474-80. https://doi.org/10.1590/S141335552011000600008 . PMid:22218712

15. Woods RT, Britton PG. Clinical psychology with elderly. Beckenham Kent: Croom Helm; 1985, p. 59. 